\title{
كشاف الناشيرين
}

01

$$
\text { • دار بدائل للطبع و النشر و التوزيع }
$$

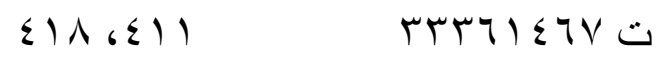

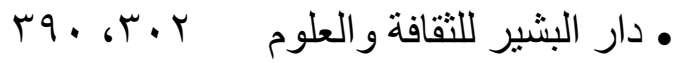

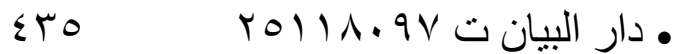

$\leq \leqslant 7$

$$
\begin{aligned}
& \text { • الدار الثقافية للنشر } \\
& \text { • دار الجامعة الجديدة } \\
& \text { ت }
\end{aligned}
$$

rN1619r6191

179

$$
\text { • دار الجامعة العربية }
$$$$
\text { • دار الجندى للنشر و التوزيع }
$$

$1 \leqslant r$

$$
.1119 \leq Y 9 \vee \wedge . ت
$$

1 .

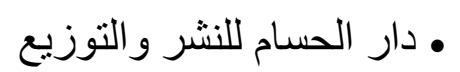

• دار الحكمة للطباعة والنشر و التوزيع ETV ، $\varepsilon Y V_{6}$ T . 1

$$
r \leqslant 1 . T \vee \leqslant \Lambda ت
$$

$$
\text { • دار دَوّن للنشر و التوزيع }
$$

rq人 r

$$
\text { • • • دار الرار الذهبية الروضيد }
$$

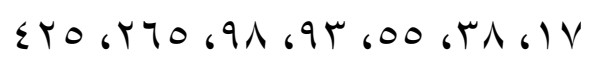

• دار سفنكس للخدمات الثقافية

rov 6 TOE 6r. O 6 TqI

• دار السلام للطباعة و النشر و التوزيع

ت

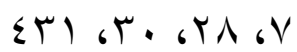

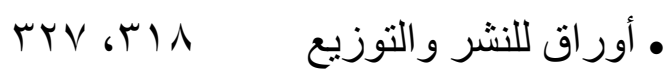
• بورصة الكتب للنشر والتوزيع $\left.r \cdot V_{6}\right) \vee q$

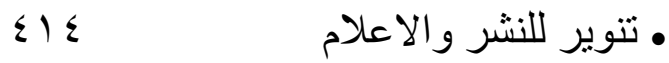

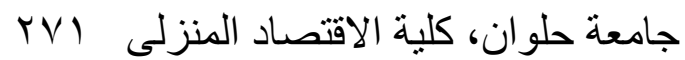

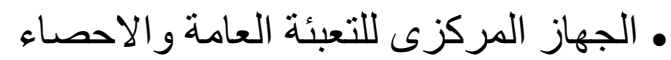
$1 \leqslant \varepsilon$

$7 \leq 69$ • - مدار الاتقان

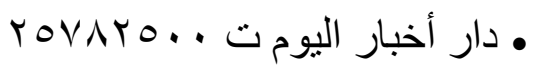

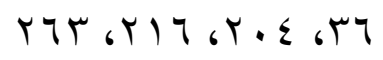

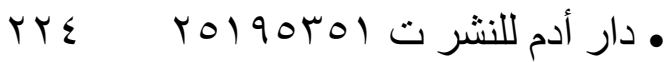

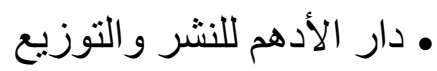
ت

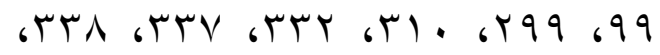
r90 6 r • دار الإسلام للطباعة و النشر

$r \leq 1$

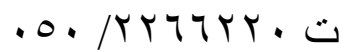
10 • دار الاصالة \&17 • دار الاصدقاء للنشر الاصله 7. • دار الافتاء المصرية

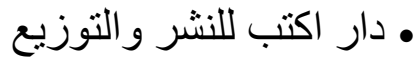
.11 .

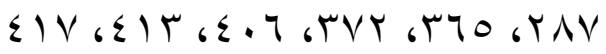
• دار الامل للطبع والتوزيع

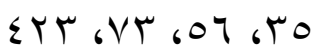
it • دار أنصار السنة المحمدية • دار الايمان و الحياة ت 


$$
\text { • دار الفكر و القانون للنشر و التوزيع }
$$

KIY 6IVT, 1096110

• بrvorq9. دار الكتاب الحديث $611 Y 69069 \leq 69 Y$ 6 $9 Y$ 6 • 6 $1 Y$ וT/ rO9 6rOT 6rT. 6rYO

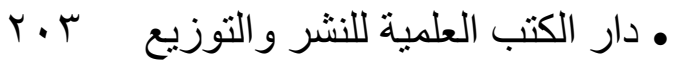

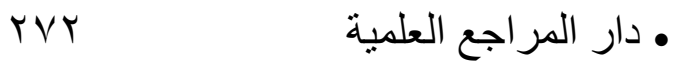
$\varepsilon \varepsilon$ • دار المشوره دار الثر إن

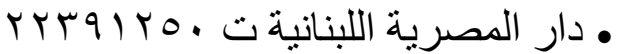
ET人,

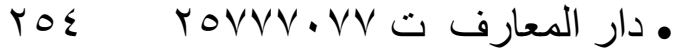

$$
\begin{aligned}
& \text { • دار محمود للنشر و التوزيع } \\
& \text { ت ت }
\end{aligned}
$$

$61 V 1617161076100610 \leqslant 6104$

$$
\text { Y17.195619. }
$$

70

$$
\text { • دار النابغة }
$$$$
\text { • دار النسيم للنشر و التوزيع دابع النه }
$$

$\varepsilon 10_{6} \leqslant \cdot r$

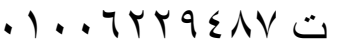

$\varepsilon \Gamma$.

• مار نشر الثقافة

人)

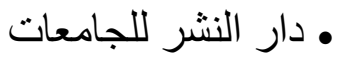

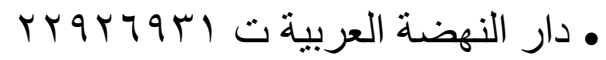

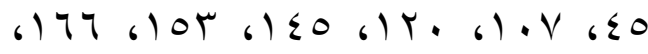

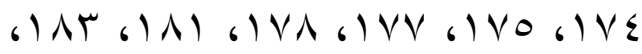

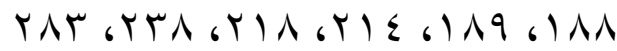

• دار نهضة مصر ت ع ع

rN

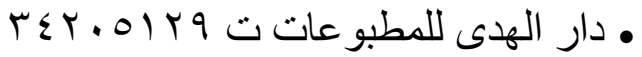
rNV
• دار شرقيات ت r ( 四

• دار الشروق ت • دار الصحوه للنشر و التوزيع 190 9

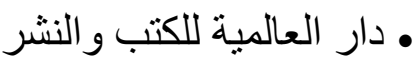
• دار العلوم العربية للنشر و التوزيع

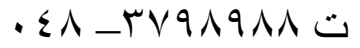
$.11 \leq \leqslant \vee T \leqslant \ldots$.

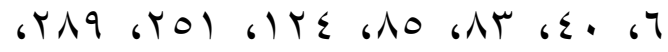
. $\varepsilon \leqslant Y_{6} \leqslant \varepsilon \cdot 6 \varepsilon+1$, $\varepsilon \varepsilon$

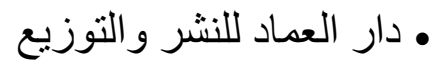

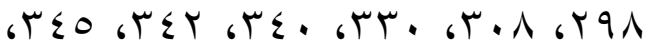
rNo r rVA • دار غراب للنشر والتوزيع ت

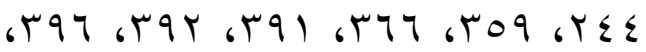
$\varepsilon \cdot \Lambda_{6} \varepsilon \cdot 0$ ، $\varepsilon \cdot r$ ، $r 99$ • دار غريب للطباعة والنشر و التوزيع

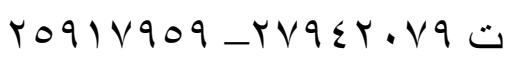

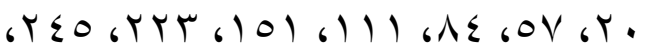
$r \leq 9, r \leq 7$ • دار الفاروق للاستثمار ات الثقافية re ت

170,114

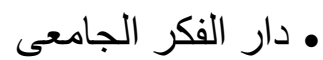
• دار الفكر العربى ت دrvorvro

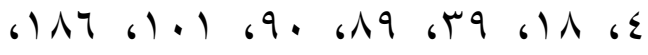
YVT GYOY GTI GYN GYT TYI. • دار فهرس للطباعة و النشر و التوزيع rrq $.11 .119077 . ت$ 


$$
\text { • المجمو عة العربية للتدريب و النشر }
$$

TYV 6 Y.96) $9 V_{6}$ (1 $\leq 1$

$$
\text { • مركز إبصار للنشر و التوزيع }
$$

ro

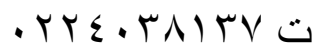

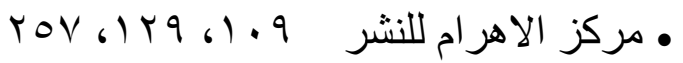

$$
\text { • المركز القومى للإصدار ات القانونية }
$$

r)

• المركز القومى للبحوث الاجتماعية بسا

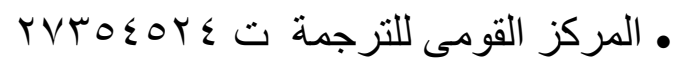
6) $\leqslant 9$ 6) $\leqslant \wedge$ 6 ITr 6Ir. 69V 6V9

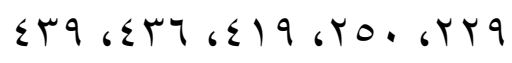

TVV 6VO

$$
\text { • مطابع دار الجمهورية }
$$

rT.

rAo

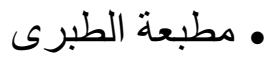

79

$$
\text { • مطبعة نوبار ديجيتال }
$$

rV

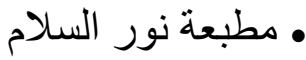

YrE

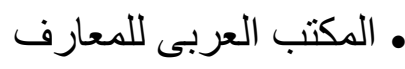
• المكتب المصرى الحديث

$1 \leq$. rrqustrv ت

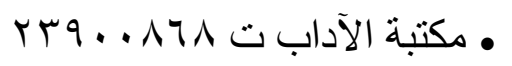

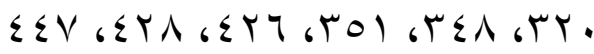

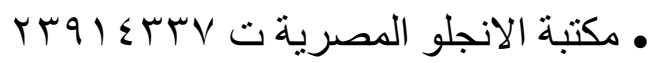

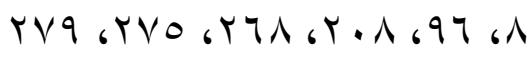

r^

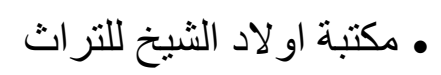

• مكتبة الإيمان للطباعة و النشر و التوزيع

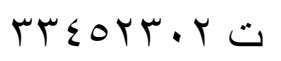

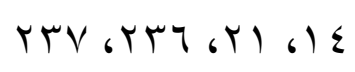

rาะ

• مكتبة البلد الامين

OT 6 T E 64

• مكتبة الثقافة الدينية البية مكتين

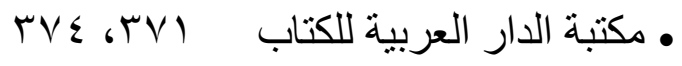

ror

• دار همسة للنشر والتوزيع

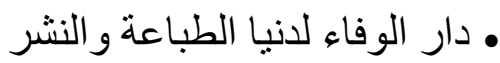
EYr GTK

TOYV $\leqslant \leqslant \mu \wedge$

• دار يسطرون للطباعة و النشر و التوزيع . . .

ت

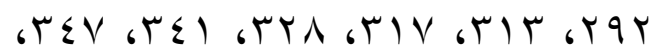

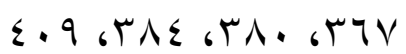

• الرواق للنشر و التوزيع

ت

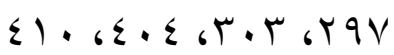

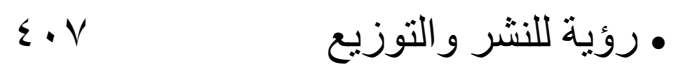

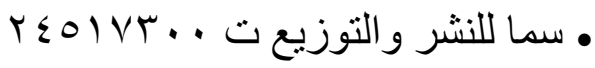
rVo 61.0

• الثركة العربية المتحدة للتسويق VE

$$
\text { و التوريدات }
$$

• شركة القصر للاعاية والاعلام

rrT

. Y Y $\leqslant \wedge V O$.VY

111

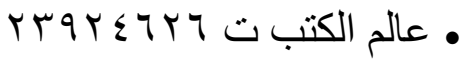

• علوم الامة للاستثمار ات الثقافية

\{Y

. r/rva人100

• عين للار اسات والبحوث الانسانية والاجتماعية

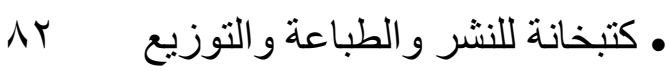
• كثيدة للنشر والتوزيع

• كلية التربية الرياضية ـ قلمم التمرينات YAT

• كنوز للنشر والتوزيع • المجلس الأعلى للتقافة ت I.

• المجمو عة الدولية للنشر و التوزيع ب آب 
$r$

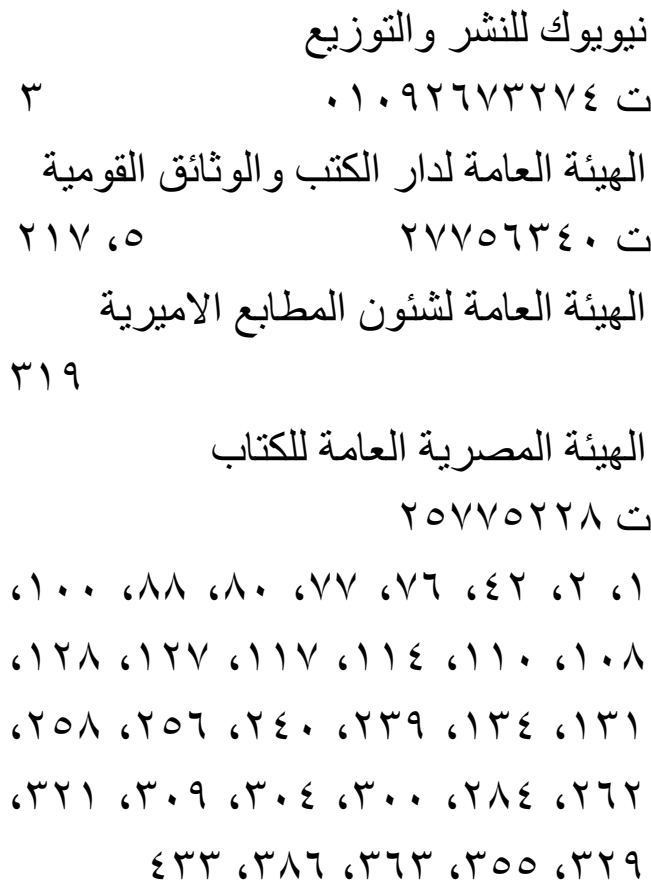

ت. ت

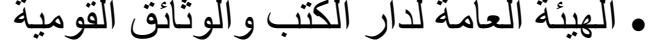

• الهيئة العامة لشئون المطابع الاميرية

• الهيئة المصرية العامة للكتاب

$$
\text { rOVROTHA }
$$

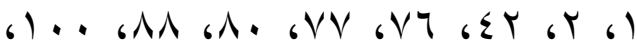

6 YN 6 IYV6 IIV6) $Y$ Y $11 \cdot 61 \cdot \Lambda$

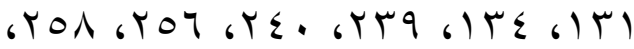

绳 r. I

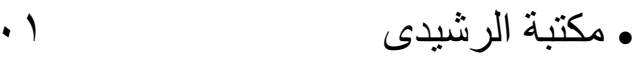

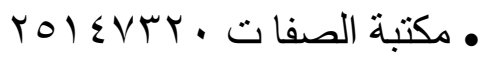

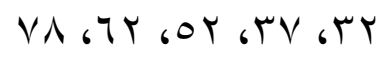
rTr • مكتبة العقيدة الاسلامية i) • مكتبة القاهرة

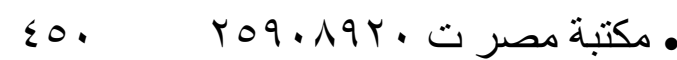
• مكتبة نانسى ت

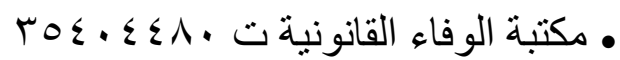
ت. . . TVRANTr 6) 671 67 $60.6 \leqslant V$ 6 $\leqslant 7$ 6 $\leqslant T$ 6). 610V 61T961TV 61T0 6119 6) VT 6) . 6ITV 6170617Y617.

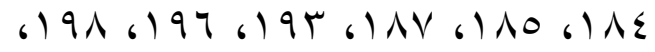
YVV 6Y7V6 Y77 6 Y.O 6 Y. Y 6 99 • منشأة المعارف ت • مؤسسة الامة العربية للنشر والتوزيع . $\leqslant \wedge$ ت

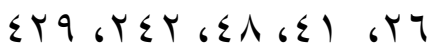

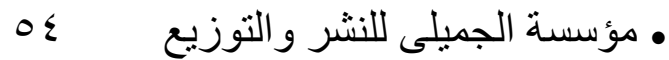
• مؤسسة حورس الدولية r. T 6 Y. . 6) 1.6$) V Y$ $0 \wedge$

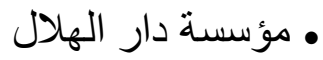

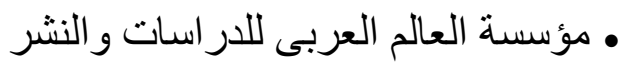
$.110 \leqslant \Lambda \cdot 1 \cdot 10$ ت

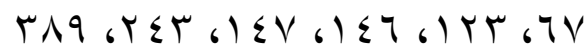
• مؤسسة عالم الرياضة TYY 6YY 6) TE

• مؤسسة علوم الامة للاستثمار ات التقافية \&) rV $9 \wedge 100 ت$ rT

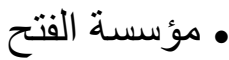

